\title{
Las Humanidades en la Universidad. La tradición humanística en la Universidad mexicana y particularmente en la Universidad Autónoma del Estado de México
}

The Humanities at the University. The humanistic tradition in the Mexican University and particularly in the Autonomous University of the State of Mexico

\section{As Ciências Humanas na Universidade. A tradição humanista da Universidade Mexicana e particularmente da Universidade Autônoma do Estado do México}

\author{
René Patricio Cardoso \\ Universidad Autónoma del Estado de México \\ E-mail: patriciocardoso@yahoo.com
}

\section{Resumen}

La tradición humanística en la Universidad mexicana y particularmente en la Universidad Autónoma del Estado de México es un ensayo que reflexiona sobre diversas concepciones que a lo largo del tiempo se han formulado sobre el humanismo y el papel que éste juega en la educación superior, esencialmente en México y particularmente en la Universidad Autónoma del Estado de México. Partimos de la visión que se impuso en México y América Latina desde el arribo de los primeros peninsulares, hasta el florecimiento de corrientes críticas y contestatarias, que han configurado un programa decolonial que podría ser impulsado en nuestras propias instituciones educativas; teniendo como meta específica, contribuir a fortalecer vínculos y la cooperación entre la Universidad Autónoma del Estado de México y la Universidad de Cuenca. 
Palabras claves: Humanismo y Educación; Humanismo y Universidad; humanismo decolonial.

\section{Abstract}

The humanistic tradition at the Mexican University and particularly at the Autonomous University of the State of Mexico is an essay that reflects on various conceptions that over time have been formulated about humanism and the role it plays in higher education, essentially in Mexico and particularly at the Autonomous University of the State of Mexico. We start from the vision that was imposed in Mexico and Latin America since the arrival of the first peninsulars, to the flowering of the critical and answering currents, which have shaped a decolonial program that could be promoted in our own educational institutions; having as a specific goal, to contribute to strengthen bonds and the cooperation between the Autonomous University of the State of Mexico and the University of Cuenca.

Keywords: Humanism and Education; Humanism and University; decolonial humanism.

\section{Resumo}

As Ciências Humanas na Universidade. A tradição humanista da Universidade Mexicana e particularmente da Universidade Autônoma do Estado do México é um trabalho que reflete várias concepções que ao longo do tempo foram formuladas sobre humanismo e o papel que desempenha no ensino superior, basicamente no México e particularmente na Universidade Autônoma do Estado do México. Nos partimos da visão que foi imposta no México e na América Latina, desde a chegada da primeira peninsular, até o florescimento de versões críticas e de respostas, que moldaram um programa descolonial que poderia ser promovido a partir de nossas próprias instituições de ensino; tendo como objetivo específico contribuir para fortalecer os laços e formas de 
cooperação entre a Universidade Autônoma do Estado do México e a Universidade de Cuenca.

Palavras-chave: Humanismo e Educação; Humanismo e universidade; humanismo descolonial.

$$
* * *
$$

\section{Introducción}

Esta invitación me ha causado una gran emoción porque me da la oportunidad de regresar a la universidad en donde me formé. Estaba recordando que hace muchos años ya, en este mismo espacio realizábamos asambleas estudiantiles, hacíamos debates; y aquí nos organizábamos para salir a las calles. La vida universitaria en esta institución me dio la oportunidad de ser lo que ahora soy. Tuve la oportunidad de estudiar Sociología y Filosofía, por lo tanto, esta es mi Alma Mater original. Pero tengo en mi historia -también- la influencia de la Universidad Nacional Autónoma de México (UNAM), que me formó como maestro y doctor. Durante casi 20 años fui profesor del Colegio de Estadios Latinoamericanos de la Facultad de Filosofía y Letras de la UNAM; y finalmente, tuve la suerte de incorporarme como profesor definitivo de la Facultad de Humanidades de la Universidad Autónoma del Estado de México (UAEM).

Estas tres instituciones me ponen una gran responsabilidad para presentarles un trabajo, que pretende ser una revisión profunda sobre algunos elementos que tienen que ver con el Humanismo y las Humanidades. Humanismo y Humanidades en los procesos educativos desde la experiencia mexicana y latinoamericana que contemple además la experiencia ecuatoriana, como parte de la totalidad de América Latina. 


\section{Dos observaciones iniciales}

La primera es una concepción sobre el tiempo. No concibo el tiempo como esa estructura lineal de pasado, presente y futuro, pues que pienso que el tiempo fundamentalmente es una estructura circular, en la cual, el pasado forma parte del presente mismo. Hace un momento escuché una alusión a Marx y decía que -para él- el pasado es una losa que pesa sobre el presente; quiere decir que el pasado está presente en el hoy; no se ha quedo como un acontecimiento que se fue. Todo pasado se manifiesta de múltiples formas en el presente y nos abre posibilidades para construir un futuro; un futuro como expectativa, que también es presente. El futuro se construye en el presente mirando hacia el pasado. Carlos Marx (1981) escribió en El 18 Brumario de Luis Bonaparte:

Los hombres hacen su propia historia, pero no la hacen a su libre arbitrio, bajo circunstancias elegidas por ellos mismos, sino bajo aquellas circunstancias con que se encuentran directamente, que existen y les han sido legadas por el pasado. La tradición de todas las generaciones muertas oprime como una pesadilla el cerebro de los vivos. (pp. 404-498)

La segunda cosa que me gustaría dejar en claro es que, el punto de vista que voy a presentar es mi punto de vista; y si ustedes están de acuerdo, o si alguno de ustedes está de acurdo, que bueno para mi, y si no están de acuerdo, mucho mejor todavía. ¿Por qué razón mejor aún? Porque quiere decir que el pensamiento sobre el humanismo y las humanidades no es homogéneo, no es monolítico y que existe la posibilidad de discrepar sobre eso. Y si existe esa posibilidad de discrepar, que no me pidan a mi, ni les pidan a los que piensan como yo, que nos alineemos a los pensamientos de grupos que desde estructuras de poder o desde alguna posición hegemónica nos pretendan imponer su pensamiento.

Quiero agradecer a mis amigas Ana Luz y Cata León, así como a Humberto Chacón, viejo amigo también; compañeros que están aquí presentes, y 
a quienes no les voy a decir Sra. Vicerrectora, ni Sr. Decano, porque estoy en contra del culto a la personalidad. Por ventaja soy su amigo y les puedo decir Cata, Humberto o Ana Luz. El culto a la personalidad debe ser combatido, pues es necesario ir deconstruyendo relaciones de poder que nos impiden pensar libremente. En general, puedo decir que la reverencia a quienes detentan el poder nos castra la posibilidad de un pensamiento autónomo, como parte de la construcción de un nuevo proyecto de humanidad.

Quisiera decir también, que las humanidades tienen que ser eminentemente subversivas. Deben subvertir todos los órdenes posibles y en todos los espacios a su alcance; porque lo humano es esencialmente transformador; ahí radica la posibilidad real de construir unas humanidades y un humanismo para el siglo XXI.

\section{La tradición humanística en la Universidad Mexicana}

El presente trabajo es un breve recorrido por el difícil camino que han recorridos las humanidades en la universidad mexicana, y particularmente en la Universidad Autónoma del Estado de México, donde se encuentra la Facultad de Humanidades.

Naturalmente que, para llegar a este momento, tendremos que referirnos al origen de la universidad mexicana, mismo que se remonta al 21 de septiembre de 155 cuando fue fundada la Universidad Real y Pontifica de México, en el entonces Virreinato de la Nueva España; pero no nos detendremos ahí, aunque habría que hacer una reflexión: ¿Qué había antes del 21 de septiembre de 1551 en estas tierras que hoy se pueden conocer como Abya Yala? ¿Había acaso, un vacío territorial con un vacío de pensamiento? ¿Existía un vacío de cultura?; si la respuesta es negativa, ¿qué pasó con esa herencia que nos legaron las culturas de los pueblos de Abya Yala? Dicho legado no fue incorporado en lo que se constituyó la tradición de las humanidades en la real y pontificia universidad, y como hemos dicho, es el antecedente de lo que hoy es la Universidad Nacional 
Autónoma de México (UNAM). Debemos reconocer, sin embargo, que, si bien es cierto, el legado de las culturas de nuestros pueblos originarios, no estaban en su origen, sí están presentes hoy, y seguirán en el futuro.

Haremos un recorrido por la universidad mexicana después de la declaratoria de independencia nacional en septiembre de 1821, poniendo atención a las posteriores reformas de Benito Juárez y al empuje que le dio Gabino Barreda, orientado por el pensamiento positivo de Augusto Comte, visión que entró en crisis junto al gobierno de Porfirio Díaz. Señalaremos algunas ideas en torno al papel que jugó el Ateneo de la Juventud, y especialmente al que desempeñó José Vasconcelos en el desarrollo de la educación y la universidad mexicana; hechos trascendentales para el desarrollo del humanismo en México, reconociendo su influencia profunda en la universidad latinoamericana, en la universidad ecuatoriana y por supuesto, en nuestra universidad, la Universidad de Cuenca.

En 1910, Justo Sierra funda la Universidad Nacional de México, pero fue el 22 de mayo de 1929 cuando Emilio Portes Gil decreta la autonomía de la Universidad, convirtiéndose en la Universidad Nacional Autónoma de México. Con Vasconcelos se consolida la UNAM, él fue quien formuló su lema: "Por mi raza hablará el Espíritu". Este lema, que me ha causado conflicto, pues unos dicen que el lema completo sería: Por mi raza mestiza hablará el espíritu universal, pero otras versiones sostienen que el lema fue: Por mi raza hablará el Espíritu Santo.

Haremos mención de los acontecimientos del 68, la huelga estudiantil de 1999, para detenernos en las formulaciones actuales y las perspectivas que las humanidades tienen en la universidad mexicana, a partir de las propuestas de la $I V$ Transformación del presidente López Obrador y los cambios que se realizan a la Constitución mexicana en esta materia, cambios impulsados por las Facultades de Filosofía y Humanidades, la Asociación Filosófica de México y el Observatorio Filosófico de México entre otras instituciones educativas del país. 
Particularmente, abordaremos la historia de la Universidad Autónoma del Estado de México, desde que fue fundado el Instituto Científico y Literario, hasta los últimos cambios realizados en la Facultad de Humanidades de la UAEM y concretamente en su licenciatura en Filosofía. Para concluir señalando algunas pautas para la discusión del futuro de las humanidades en nuestras universidades y específicamente una propuesta para establecer mayores relaciones de cooperación académica entre la Universidad Autónoma del Estado de México y la Universidad de Cuenca.

\section{El Humanismo y las Humanidades en la Universidad}

Para hablar sobre las humanidades en la universidad, es necesario, en primera instancia, reflexionar sobre el humanismo. Concepto-categoría que a lo largo de nuestra historia a desempeñado un papel fundamental en las distintas sociedades y que, a pesar de su trascendencia -o posiblemente por ella-, no ha estado exenta de complejos debates sobre su sentido y comprensión.

Planteamos, en primer lugar, un conflicto metodológico. ¿Cómo y desde dónde pensar el humanismo? ¿Cómo y desde dónde pensar las humanidades? Si pensamos, por ejemplo, desde la Sorbona de París, o si pensamos desde la UAEM, o si lo hacemos desde la Universidad de Cuenca, vamos a tener conclusiones distintas, porque ecuatoriano desde Cuenca, es diferente de lo mexicano desde Toluca; y porque ambos son distintos a lo francés. Los problemas de los parisinos son suyos, y los de los cuencanos son nuestros, aunque mucho podamos compartir con ellos.

Como decía Martí, no podemos resolver nuestros problemas con las ideas de Paris; por lo tanto, el humanismo que debemos producir es un humanismo sobre nuestras propios experiencias y necesidades. Es falso sostener que lo humano es universal; lo humano no puede universal 
porque los sujetos que constituyen esa humanidad somos de carne y hueso, somos distintos, estamos en distintos lugares, y pensamos y sentimos diferente.

Por ejemplo, al preparar este escrito, recordé un trabajo de Gabriel Méndez Plancarte, (1945) Los Fundadores del Humanismo Mexicano, donde afirma que: [...] el humanismo grecolatino es una de nuestras más hondas y fecundas raíces, uno de los elementos vitales y específicos que han plasmado nuestra fisonomía espiritual y han contribuido a formar lo que bien podemos, sin rústica jactancia, llamar la cultura mexicana. (p. 242)

Y en el Índice del Humanismo Mexicano - dice-, "me atreví a esbozar un panorama del no interrumpido desarrollo de esa tradición humanística en México, desde el siglo xvi hasta nuestros días". (Méndez, 1944, p. 47). Por supuesto que muchos estarán de acuerdo con afirmaciones de este tipo, pero muchos otros no compartiremos dicha forma de pensar. Para nosotros, la posibilidad de avanzar en la construcción de un humanismo como categoría y concepto contemporáneo, como una forma de entender el mundo parte del desacuerdo con dicha tradición. Que pueden estar establecidos en nuestras universidades, que pueden formar parte de nuestras normas y que pueden incluso formar parte de nuestras leyes, no garantiza la certeza y universalización de aquellos conceptos. Hay que subvertir esas formas de pensar, aunque subvertirlas implique, incluso arriesgarse. Muchos han sido expulsados de las universidades en distintos tiempos por pensar distinto a los regímenes. Un ejemplo podría ser lo sucedido en 1968 en México.

\section{Orígenes de la Universidad Mexicana}

E1 21 de septiembre de 1551, por Cédula Real de Felipe II, sobre lo que hoy son los vestigios arqueológicos de la vieja México -Tenochtitlan, se fundó la Real Universidad de México, aunque no fue inaugurada sino hasta el 25 de enero de 1553, inspirada en las tradiciones de las universidades medievales; con cuatro facultades mayores: Teología, 
Cánones, Leyes y Medicina; y una facultad menor, la de Artes; además, se impartían clases sueltas de lenguas indígenas, astrología y otras. A la Real Universidad de México se le agregó el calificativo de Pontificia, en 1559, gracias a una Bula del Papa Clemente VIII, constituyéndose como la Real y Pontifica Universidad de México, la que con no pocos esfuerzos permanecería abierta hasta el 30 de noviembre de 1865 , fecha en la que fue cerrada por disposición de Maximiliano de Habsburgo. ${ }^{1}$ La universidad copió lo administrativo de la Universidad de Bolonia y lo educativo, de la Universidad de Paris; con una metodología didáctica tradicional, medieval-escolástica. (Escuela Cima, s/f.)

En la Real y Pontifica Universidad de México se formaron teólogos y algunos miembros de la burocracia novohispana. (Marsiske 2006) Las universidades en México, como todas aquellas que se crearon durante la época colonial, tenían una función básica: contribuir a la creación de las mejores condiciones ideológicas para favorecer la dominación ideológica de los pueblos originarios de lo que hoy se reivindica como Abya Yala. En una reseña de Graciela Bellón al libro titulado La universidad de México. Un recorrido histórico de la época colonial al presente, (Marsiske, 2006) señala que, durante el periodo colonial,

[...] la Universidad jugaría un papel clave en el eje que quería la Corona para la Universidad: además de encargarse de la educación de los naturales de la tierra y de los hijos de los españoles, debía procurarse que la evangelización de los indios estuviera a cargo del clero secular, por lo cual se requirió que los clérigos se formaran en la Universidad para poder consolidar a la nueva iglesia. (p.18)

1. El 28 de octubre de 1538, mediante la bula papal In Apostolatus Culmine, se fundó en Santo Domingo la Universidad de Santo Tomás de Aquino, aunque no recibió el reconocimiento oficial del Reino de España hasta 1558; esta universidad adoptó el modelo la Universidad de Alcalá de Henares. La Cédula Real del 12 de mayo de 1551 creó la Universidad de San Marcos de Lima, que a la postre fue conocida como "Real y Pontificia Universidad de la Ciudad de los Reyes de Lima”. 
Estas prácticas educativas llevaban aparejado el combate a todo lo que la Iglesia denominaba paganismo y herejía. En ejemplo de lo dicho fue el acto de barbarie cometido por el franciscano Diego de Landa, obispo de la arquidiócesis de Yucatán el 12 de julio de 1562 con el denominado Auto de fe de Mani. ${ }^{2}$ Sin embargo, es necesario resaltar que en este período contamos con destacados humanistas de la talla de Fray Bartolomé de las Casas, Vasco de Quiroga, o Fray Juan de Zumárraga, entre otros. De las Casas que se destacó por la famosa controversia con Ginés de Sepúlveda, en torno a la naturaleza de los indios; polémica que a juicio de Enrique Dussel constituye el inicio de la modernidad, desde América Latina. Es el primer momento en el que se empieza a discutir sobre la naturaleza de los indios, tema que dista mucho de ser clerical.

Juan de Zumárraga, uno de los fundadores del Colegio Imperial de Santa Cruz(1536), se consagró a la educación superiorde los indígenas, marchando en contracorriente de la época. Digamos de paso que es una equivocación referirse a los habitantes de estas tierras como indios o indígenas, aunque Colón haya pensado que llegaba a las Indias Occidentales; pero no solo por eso, sino porque existía la necesidad de eliminar la cultura de estos pueblos, y esto se conseguía dándoles un calificativo que los homogenice, haciendo que todos tengan la misma característica, la misma naturaleza, la misma humanidad: bárbaros, que se enfrentaban a la civilización. Pero como la prosperidad económica del virreinato dependía de que se garantice a los españoles una posición privilegiada, por encima de los indígenas, las autoridades virreinales retiraron el apoyo económico al Colegio de Tlatelolco y ordenaron que ya no se impartieran clases de humanidades y teología, para quedarse solamente con la enseñanza del catecismo a los niños indígenas. (Rojas, 2016, p.436)

Un intento importante de reconfigurar el humanismo pontificio y real que imperaba en la época se produjo a partir de 1572, con la llegada de la

2. El auto de fe de Maní ocurrió en la provincia de Yucatán, México, el 12 de junio de 1562 y consistió en la quema de un número considerable de imágenes de culto, objetos sagrados y códices de la cultura maya. 
Compañía de Jesús a la Nueva España, que puso nuevamente en evidencia el dilema planteado desde los primeros años de conquista: priorizar la educación indígena o mejorar el nivel cultural de los criollos. A decir de Rojas Galván, (2016) "la educación humanista que impartieron los jesuitas desde su arribo a la Nueva España, hasta su expulsión en 1767, facilitó, por un lado, la integración social, y por otro, la promoción social de los que formaban parte de grupos sociales populares”. (p. 439)

En 1778 fue abierta la Real Escuela de Cirugía y en 1792 el Real Colegio de Minería. Dos años más tarde fue establecida la Academia de San Carlos, para el estudio de las Bellas Artes. Este es un programa del crecimiento de las humanidades en la universidad mexicana. No se pretendía en ese momento establecer la facultad de humanidades, pero estaban definiendo programáticamente lo que constituía para ese momento las humanidades.

\section{El Positivismo y su repercusión en América Latina}

El positivismo, durante el siglo XIX jugó un papel crucial para el desarrollo de las humanidades en toda Latinoamérica; y podemos decir que el cultivo y la difusión de cierto humanismo, en la Nueva España, por ejemplo, como en toda América Latina, no se modificó significativamente hasta bien avanzado el siglo XIX.

Después de la escolástica, -dice Leopoldo Zea (1976)ninguna otra corriente filosófica ha llegado a tener en Hispanoamérica la importancia que tuvo el positivismo. Por lo que se refiere a la escolástica, su arraigo y vigencia dependieron de la concepción que sobre el mundo y la vida tuvieron los pueblos que conquistaron y colonizaron esta parte de América (p.77)

A inicios del siglo XIX, México atravesaba por un proceso de definiciones importantes, pues recién se había incorporado a la vida independiente. Los cambios impulsados desde el Grito de Dolores (1810) hasta 
septiembre de 1821, cuando el Ejército Trigarante bajo el mando de Agustín de Iturbide entró triunfante en la ciudad de México no cubrieron las expectativas anheladas. La independencia no se consolidó en toda su magnitud. El mismo Iturbide, que había participado en las luchas por la independencia de México años atrás, -1822- fue proclamado y coronado emperador, con el nombre de Agustín I, aunque abdicó en marzo de 1823. Desde ese momento, hasta finales del siglo, la inestabilidad política en el país fue una de sus principales características.

Esta circunstancia sirvió para que muchos historiadores plantearan que, si habíamos logrado la independencia política, había que luchar por la independencia mental. Independencia mental que no quería decir asimilémonos de lo europeo; quería decir: reconozcámonos como sujetos productores de identidad, como sujetos productores de cultura, como sujetos productores de humanismo, y desde esta parte de la tierra presentémonos al mundo como lo que somos. El nuestro humanismo, desde esa perspectiva tenía que ser anticolonial, tenía que ser anticlerical, y estar en contra de las distintas formas de dominación que imperaban es la época. Debía, por tanto, incorporarse a los procesos de liberación de todos los sujetos, hombres y mujeres, en todos los espacios de la vida de América Latina, lo que incluye la educación y las universidades.

Fue con Benito Juárez que México adquirió cierta estabilidad política; y también con él, un conjunto de transformaciones impulsadas por las Leyes de Reforma. Él fue quien en 1867 nombró a Gabino Barreda como director de la Escuela Nacional Preparatoria y desde ese momento, Barreda y el positivismo fueron ganando espacio en la educación mexicana hasta convertirse en los pilares centrales de la educación mexicana. Al concluir su conocido discurso Oración Cívica (1867) Barreda dijo: "que en adelante sea nuestra divisa libertad, orden y progreso; la libertad como medio; el orden como base y el progreso como fin ...". (p. 18)

Con Juárez, dice Gabriel Vargas Lozano, (s/f) inicia en México el proceso de construcción de la modernidad, apoyándose en las ideas de 
la Ilustración: el liberalismo y el positivismo; especialmente en los tres grandes pensadores que influyeron en la educación, en la política y en la ideología en México y América Latina: Augusto Comte (1798-1857); John Stuart Mill (1806-1873) y Herbert Spencer (1820-1903). "Precisemos que los tres autores mencionados comparten las concepciones básicas del positivismo, pero tienen entre sí posiciones encontradas sobre diversos temas como sería su concepción de la sociedad". (p.1)

Tanto la escolástica como el positivismo se empeñaron en negar la existencia o valides de concepciones, prácticas y tradiciones de pueblos que habitaron Abya Yala, anteriores a 1492. Pareciera que no existía nada antes de Colón. Sin embargo, multitud de prácticas y cosmovisiones permanecieron ocultas y en la resistencia; no han desaparecido versiones del humanismo que practicaban nuestros pueblos originarios; esas cosmovisiones viejas en las cuales, la idea de la circularidad del tiempo ya estaba presente.

Del positivismo latinoamericano podríamos destacar figuras como Gabino Barreda (1820-1881) en México, Enrique José Varona (18491933) en Cuba, Belisario Quevedo (1883-1921) en Ecuador, José Enrique Rodó (1871-1917) en Uruguay, José Victoriano Lastarria (1817-1888) en Chile, o José Ingenieros (1877-1925) en Argentina, por mencionar algunos. Esta corriente posibilitó un eficiente combate a la Escolástica; filosofía que había predominado en América Latina durante siglos. Gracias a ideas como éstas, se logró arrebatarle a la Iglesia Católica el monopolio de la educación, la cual pasó a ser obligación del nuevo estado laico. Por otro lado, se buscaba en la educación estatal un carácter científico y universal.

El positivismo argumentaba que la verdadera libertad no puede consistir más que en la sumisión racional a las leyes de la naturaleza, y que los fenómenos del mundo debían verse como sucesos regulados por leyes universales. Postulaba que el conocimiento científico debe basarse en los hechos comprobados por la experiencia; siendo esto válido tanto para los 
fenómenos de la naturaleza como los de la sociedad. Pero no se habían dado cuenta que, muchas veces nuestros propios sentidos nos engañan, por ejemplo, la visión: cuando en las noches estrelladas miramos las cielo, no nos damos cuenta que no estamos viendo las estrellas, creemos que las estamos viendo, pero es la luz que esas viejas estrellas nos mandaron lo que vemos, y cuando su luz llega a nuestra retina pensamos que en ese momento ellas están en aquel lugar que las miramos. No es cierto que cuando uno mire las estrellas ellas ahí están. El sol que es la más cercana de las estrellas está a ocho minutos de distancia de tiempo de cuando lo miramos.

Una de las tesis centrales del positivismo dice que para cualquier tipo de conocimiento válido existe solamente una posibilidad: utilizar el método científico, que en lo fundamental se basa en la observación, la experimentación y/o la comprobación de los hechos. El positivismo postulaba que la realidad tiene un orden único que tiende al progreso; $\mathrm{y}$, que dicho progreso debe alcanzarse sin destruir el orden establecido. Afirmaba también que el verdadero conocimiento, el conocimiento científico es atemporal, pero tiene valor universal. Sin embargo, como afirma Leopoldo Zea (1985), el positivismo, más bien fue utilizado como instrumento para consolidar el poder de un grupo político-social en su pugna con otros grupos; y aunque en sus inicios estuvo vinculado al nombre de Juárez, en México es imposible desligarlo del porfirismo y el grupo político de los científicos. ${ }^{3}$

En 1878, cuando apenas asumía el poder el general Porfirio Díaz, surgió en la capital mexicana un nuevo grupo político que se manifestó en el periódico La Libertad; que tenía como lema central "orden y progreso". El Nuevo grupo se autodenominó conservador-liberal; para ellos su meta era la libertad, pero con métodos conservadores; es decir, se oponían a los métodos revolucionarios y apostaban por la evolución.

3. Entre los "científicos" más destacados que se integraron al gobierno de Porfirio Díaz en el último período, podemos mencionar a: José Ives Limantour, Justo Sierra, Pablo Macedo, Miguel Macedo, Joaquín Diego Cassasús, Ramón Parra y otros. 
El orden que postula La Libertad consistía en eliminar de una vez por todas la anarquía, que según ellos había caracterizado el período liberal, al amparo de la constitución de 1857. Justo Sierra, el mismo que había colaborado con Benito Juárez, aunque más tarde adoptó posiciones conservadoras, llegando a ser Subsecretario de Instrucción Pública y posteriormente Secretario de Instrucción Pública y Bellas Artes, refiriéndose a los constituyentes del 57, afirmó lo siguiente:

Nuestra ley fundamental, hecha por hombres de raza latina, que creen que una cosa es cierta y realizable desde el punto de vista de que es lógica; que tienden a humanizar bruscamente y por la violencia cualquier ideal; que pasan un día del dominio de lo absoluto al de lo relativo, sin transiciones, sin matices y queriendo obligar a los pueblos a practicar lo que sólo resulta verdad en las regiones de la razón pura; estos hombres, quizá nosotros somos de ellos, que confunden el cielo con la tierra, nos hicieron un código de alianza elevado y noble, pero en el que todo tiende a la diferenciación, a la autonomía individual llevada a su máximo, es decir, al grado en que parece cesar la acción de los derechos sociales y todo se convierte en derechos individuales. (Citado en Zea, 1976 p. 155)

Justo Sierra postuló un nuevo orden que limitaba las libertades del pasado. En este afán se configuró lo que se denominó tiranía honrada, misma que se iba a encarnar en el gobierno del general Porfirio Díaz, quien llega al poder el 26 de noviembre de 1876, después de levantarse en armas contra el gobierno de Sebastián Lerdo de Tejada. Con Díaz empezaba la era de los científicos, pero al mismo tiempo, el surgimiento de la reacción antipositivista concretada en el Ateneo de la Juventud.

Uno de los principios que Sierra defendió para la fundación de la Universidad Nacional fue el principio de laicidad. En su argumento ante los diputados, Sierra expuso lo siguiente: 
Una Universidad es un centro de donde se propaga la ciencia, en que se va a crear ciencia; ahora bien, señores diputados, la ciencia es laica, la ciencia no tiene más fin que estudiar fenómenos y llegar a esos fenómenos últimos que se llaman leyes superiores. Si la ciencia es laica, si las universidades se van a consagrar a la adquisición de las verdades científicas, deben ser, por la fuerza misma del término, instituciones laicas. (Citado en Valadés, 2014, p. 437)

La Universidad Nacional Autónoma de México fue fundada el 22 de septiembre de 1910, dando cumplimiento al decreto del 26 de mayo, que formalizaba su Ley Constitutiva presentada por Justo Sierra. Con esa ley, las escuelas de Bellas Artes, Nacional Preparatoria, de Ingenieros, de Medicina y de Jurisprudencia pasaron a formar parte de la Universidad. También se creó la Facultad de Altos Estudios, con la Sección de Ciencias Exactas, Físicas y Naturales.

En 1929, se incorpora la Escuela Nacional de Medicina Veterinaria, la Dirección de Estudios Biológicos, con el nombre de Biología; el Observatorio Nacional, y el Departamento de Exploraciones y Estudios Geológicos, con el nombre de Instituto de Geología; se crea la Facultad de Comercio y Administración, y la Escuela Nacional de Jurisprudencia, al mismo tiempo que cambia de nombre a Facultad de Derecho y Ciencias Sociales, funda su Sección de Economía. El 6 de junio de este año se estatuye la autonomía universitaria. (Bautista, 2008).

La Facultad de Filosofía y Letras de la UNAM se fundó en 1924, teniendo como antecedente a la Escuela Nacional de Altos Estudios de la Universidad fundada en 1910. Su objetivo desde un principio fue: prolongar el legado histórico de la cultura humanística, a más de impulsar la reflexión crítica sobre temas relacionados con el pensamiento, la educación y la creación artística.

En 1934, adquirió el nombre de Facultad de Filosofía y Bellas Artes y quedó conformada por la Escuela Nacional de Arquitectura, la Escuela 
Nacional de Artes Plásticas, la Escuela de Filosofía y Letras y la Escuela Superior de Música. En 1936, la facultad cambia su nombre y fue conocida como Facultad de Filosofía y Estudios Superiores. En 1938 retoma el nombre de Facultad de Filosofía y Letras.

\section{Crisis del positivismo mexicano y el Ateneo de la Juventud}

El positivismo entró en crisis justamente por su formulación epistemológica que dejaba fuera del espacio lo humano, la cultura se quedaba sin cabida, porque no había como verificar empíricamente lo que los humanistas estaban pensando. Fue cuando el Ateneo de la Juventud, constituido por un grupo de intelectuales, cuestionaba el positivismo; pero lo cuestionaba porque era un reclamo existencial; no era un cuestionar sin sentido. Fundamentalmente porque el positivismo les había dejado fuera de la historia y todos los sujetos, todos los grupos humanos necesitan encontrar en la historia su momento, porque eso les da vida. Y porque la vida, como plantea el Sumak Kawsay es el elemento que nos hace avanzar hacia un futuro con sentido.

Hay mucha información sobre el Ateneo, por lo que no vamos a detenernos en esto. Nos referiremos más bien a Vasconcelos, un personaje muy importante en la historia de la cultura latinoamericana; él postulaba que la universidad estaba obligada a comprender que el Espíritu es la máxima expresión de la Raza cósmica, la Raza universal. Pensaba que todas las razas que existieron a lo largo de la historia de la humanidad iban a dar lugar a una raza superior, una raza síntesis de las demás, que era el futuro de la humanidad. Naturalmente, no se había dado cuenta que dicha forma de pensar eliminaba la diversidad, y ponía en peligro el futuro de la humanidad, pues pensaba en una raza hegemónica.

En otro ámbito de cosas, Vasconcelos se da cuenta de las grandes diferencias entre México y Estados Unidos, y concluye que México está atrasado, que deberíamos ir hacia el progreso, por lo que propone un proyecto educativo que se adelante en el tiempo. De ahí nació la 
Universidad Nacional Autónoma de México, en la cual, años mas tarde se integraría el Colegio de Estudios Latinoamericanos, espacio dónde germinarían los aportes que hoy conocemos como la Historia de las Ideas, corriente tan amplia, de la cual muchos de quienes estamos aquí, hemos participado. La historia de las Ideas significó un viraje epistemológico que permitió construir nuevos espacios para el desarrollo de las humanidades. Espacios que repercutieron de forma importante en toda América Latina, y no solo en América Latina, sino en Europa y el mundo entero. Y nuestra facultad, la facultad de Filosofía empezó a estudiar historia de las ideas, yo mismo en estas aulas conocí a Leopoldo Zea; tuve la oportunidad de ser alumno suyo en el Colegio de Estudios Latinoamericanos de la UNAM y tuve la posibilidad de comprender que el pensamiento latinoamericano, entre otras corrientes del pensamiento.

Regresando un poco al positivismo. El positivismo en México -dice Zea, (1968)- fue combatido duramente por distintos grupos políticos y religiosos; pero hubo uno, formado en su propio seno. "Se trata de un grupo de jóvenes que se sintieron estrechos dentro de la filosofía que los había inculcado. [...] Se trata de una generación de autodidactas, de hombres que tuvieron que buscar fuera de la circunstancia cultural en que se encontraban una nueva forma de sentir la vida. Este grupo fue el de la generación llamada del Ateneo de la Juventud"; pero como dice más tarde, no se trataba solamente de una generación, sino de una nueva generación de la cual era expresión la del Ateneo. (p. 29)

El Ateneo surge en un momento clave de la historia de México; por un lado, el gobierno de Porfirio Díaz entraba en su fase final, y por otra, se estaban consolidando las condiciones que harían posible la Revolución Mexicana. Además, aparece cuando la propia doctrina estaba en decadencia, pues dejó de ser la filosofía del progreso suponer que éste ya se había alcanzado. Una vezalcanzados los fines perseguidos, dice Zea, la teoría se convirtió en algo muerto: ya no había problemas que resolver, todo había sido resuelto por el método, tal como lo había enseñado a practicar Gabino Barreda (Zea, 1968, p. 434). 
Todo lo que no podía ser explicado por el método positivo era rechazado por metafísico; de este modo, las manifestaciones del espíritu humano, así como todos los ámbitos de la cultura perdieron sentido; principio contra el cual los ateneístas se revelaron, a tal punto que como dice García (1922), "el interés de los ateneístas terminó en descubrimiento de las humanidades y la filosofía" que prácticamente había desaparecido. "Modernismo literario y antipositivísmo filosófico, agrega eran interpretados por muchos intelectuales de la época como manifestaciones de una misma tendencia histórica general, caracterizada por la vuelta a los valores espirituales y estéticos, a la que se denominó «renacimiento idealista»» (p. 3)

Los ateneístas pensaban que con ellos se habría una nueva etapa del pensamiento en México; y aunque no necesariamente estuvieron vinculados con la oposición al gobierno de Díaz, Vasconcelos buscó integrarse al grupo con el nuevo régimen, "poniendo en paralelo la «revolución antipositivista» del Ateneo con la «revolución anti porfirista» de Madero". Entre los personajes más destacados, lo que no resta importancia de otros, podemos señalar a Alfonso Reyes, Antonio Caso, José Vasconcelos y Pedro Henríquez Ureña. También podemos recordar a Jesús T. Acevedo, Alfonso Cravioto, Diego Rivera, Ángel Zárraga e Isidro Fabela.

José Vasconcelos fue un destacado intelectual que aportó mucho a la trasformación de la educación mexicana, sus aportes rebasan los realizados en el Ateneo de la Juventud y su apoyo político a Madera, en tiempos difíciles para el país. En el gobierno del presidente interino Adolfo de la Huerta fue nombrado Rector de la Universidad Nacional de México; y en el de Álvaro Obregón, Secretario de Instrucción Pública, en cuyo ejercicio realizó la primera reforma educativa de grandes dimensiones después de la Revolución Mexicana. En 1921 contribuyó a la fundación de la Secretaría de Educación Pública.

Pensaba que había que reconocer lo mexicano, estudiarlo y difundirlo; y a partir de ello construir un esquema de educación propio, sin copiar modelos extranjeros, tanto en organización escolar, contenidos y 
métodos educativos. La educación, para él, debía devolver la confianza a los mexicanos y abandonar el complejo de inferioridad. Imaginario que habría que ponerlo en duda.

Vasconcelos -dice Josefina Vásquez (1970)- veía con una gran claridad los múltiples aspectos del problema mexicano: educación indígena para asimilar la población marginal; educación rural para mejorar el nivel de vida del campo mexicano; educación técnica para elevar el de las ciudades; creación de bibliotecas; publicación de libros populares; popularización de la cultura, etc. (p. 138)

Haciendo una síntesis de los aportes de Vasconcelos a la educación y las humanidades en México, el colombiano Javier Ocampo López (2005) escribe los siguiente:

En la Historia de la Educación Iberoamericana, el humanista y educador José Vasconcelos, es el filósofo del nacionalismo y de la iberoamericanidad, en un pueblo mestizo producto del hibridismo de tres pueblos y culturas. En su obra educativa en el primer lustro de la Década de los Veinte en México, se propuso hacer de la escuela una casa del pueblo y del maestro un líder de la comunidad. Después de la Revolución Mexicana, Vasconcelos fortaleció la identidad del país azteca y en su pensamiento y acción educativa se propuso señalar a los mexicanos y a los iberoamericanos que el estímulo a la educación es el único camino para superar la crisis nacional y alcanzar la meta del desarrollo y progreso de estos países. Su gran gestión en la Universidad Nacional de México y en la Secretaría de Instrucción Pública, que lo llevó a elevar el nivel educativo y cultural del pueblo mexicano, lo convirtió en el ejemplo para los estadistas y educadores en este pueblo de Iberoamérica que transmite hacia el futuro la esencia de una "Raza cósmica", síntesis de la cultura universal. (p.159)

Aunque hoy podríamos estar en desacuerdo con muchas de las cosas que escribió Vasconcelos, no podemos desconocer que fue un aporte 
fundamental a la presencia de las humanidades en la educación mexicana. Sin embargo, es indispensable señalar que en esta misma dirección abonaron otros procesos históricos, reconfigurando las visiones que sobre el humanismo y las humanidades se han tenido. Nos referiremos rápidamente a algunos procesos.

\section{Los movimientos estudiantiles del 68 y de 1999 en México}

El Movimiento del 68 en México de gran envergadura, que transformó la vida social y política del país, a tal punto que podríamos decir que uno era el México antes de 1968 y otro el posterior. Dicho movimiento buscaba un cambio profundo en la vida política y social del país; pugnaba por mayores libertades civiles y políticas, y la disminución de tan grandes desigualdades que caracterizaban al México de la época. Buscaba la libertad de los presos políticos, la disminución del autoritarismo político ejercido durante años por el partido en el poder; y contó con la amplia participación del movimiento estudiantil, destacándose la Universidad Nacional Autónoma de México, El Instituto Politécnico Nacional, La Universidad Autónoma de Chapingo, la Michoacana de San Nicolás de Hidalgo, la Benemérita Universidad Autónoma de Puebla, la Escuela Nacional de Antropología e Historia, entre otras Universidades públicas y privadas.

Los estudiantes realizaron durante varios meses un conjunto de manifestaciones de protesta por la situación política del país, en solidaridad con la Revolución cubana y aspectos puntuales como la la derogación de los artículos 145 y a45 bis del Código Penal Federal, que instituían el delito de disolución social; la destitución de los jefes de policía, etc. Sin embargo, la intolerancia política del gobierno de Gustavo Díaz Ordaz y la rigidez del sistema político, condujeron a la masacre del 2 de octubre, en la que murieron un número indeterminado de personas, que según diversas fuentes podrían situarse alrededor de las 3.500, aunque Díaz Ordaz reportó al día siguiente la muerte de solo 26 personas. 
Los acontecimientos del 68 sacudieron la conciencia moral de todo el país, impactaron en el continente y repercutieron a escala mundial, por lo que se convirtió en un suceso que contribuyo a la transformación política de México

\section{Los acontecimientos de 1999 en la Universidad Nacional}

El 15 de marzo de 1999, el Consejo Universitario de la UNAM, presidido por su rector el Dr. Francisco Barnés de Castro, aprobó la reforma al Reglamento General de Pagos, con lo que se imponía el alza de las cuotas de la UNAM; acto que fue considerado por los estudiantes como un paso hacia el proceso de privatización de la enseñanza universitaria, aspiración que había sido defendida durante años por los estudiantes, junto a la autonomía universitaria. La medida del rector Barnés se inscribía en el sistema político autoritario y en las nuevas políticas que en el campo educativo debía realizar el gobierno de México para estar en sintonía con el Tratado de Libre Comercio, que el gobierno de Carlos Salinas había firmado en 1992 y que entró en vigor el 1 de enero de 1994.

La huelga estudiantil en contra de la reforma del Reglamento General de Pagos o simplemente alza de las cuotas de estudio, inició el 20 de abril de 1999, pero no solo se limitó a la abrogación del RGP, sino que buscó la recuperación del pase automático, eliminado en 1997; la propuesta de un Congreso democrático y resolutivo; el desmantelamiento del aparato represivo establecido por las autoridades universitarias; la ruptura definitiva de la UNAM con el CENEVAL (Centro Nacional de Evaluación para la Educación Superior A.C.), con todas sus implicaciones; y, la libertad de todos los presos políticos.

La intransigencia de las autoridades universitarias, su falta de disposición al dialogo, entre otros elementos, desencadenaron una huelga general que duró hasta el domingo 6 de febrero del 2000, cuando, por órdenes del presidente de la República, Ernesto Zedillo Ponce de León, la Policía 
Federal Preventiva ingresó a la Universidad Nacional, detuvo a más de 700 estudiantes y la intervinieron hasta el 23 de abril de dicho año. (Desinformémonos, 2019)

\section{La creación del Colegio de Estudios Latinoamericanos}

En el proceso de la recuperación del pensamiento latinoamericano, como fundamento de una perspectiva política y metodológica distinta, se encuentra la creación de instituciones que trascienda lo estrictamente nacional y adquieran una proyección internacional. Estas instituciones, gracias a su práctica intelectual y académica, sirvieron de eslabones para la toma de conciencia de nuestra latinoamericanidad, y sin señalarlo expresamente, como un paso importante en el camino de búsqueda de la decolonialidad, bajo el impulso de intelectuales de la talla de Pablo González Casanova y Leopoldo Zea. Precisamente Zea, (1977) refiriéndose a este proceso y particularmente a la creación del Centro Coordinador y Difusor de Estudios Latinoamericanos - CCyDEL- de la UNAM, dice lo siguiente;

El Centro (CCyDEL) -dice- es una vieja idea que surgió en 1945, cuando me fui en un viaje por toda América Latina para escribir un libro que hoy lleva el título de El Pensamiento Latinoamericano. En esa ocasión tuve la oportunidad de conocer a varios pensadores y filósofos con las mismas inquietudes: Francisco Miró Quesada, José Luis Romero, Cruz Costa, Arturo Ardao y otros, con los cuales se formó una especie de equipo de trabajo en esos temas, que dura hasta la fecha. A mi regreso, en 1946, pedí al entonces director de la Facultad, Samuel Ramos, me permitiese crear un Seminario de Historia de las ideas en América Latina, lo que aceptó con mucho gusto. En 1947 al Dr. Silvio Zavala, de la Comisión de Historia del Instituto Panamericano de Geografía e Historia, la creación de un comité de Historia de las Ideas en América Latina, que me permitiese coordinar las relaciones que yo había encontrado en los países latinoamericanos y el seminario que ya se ofrecía en la Facultad. (Machuca, 2007) 
La creación del Centro permitió, a su vez, el surgimiento del Colegio de Estudios Latinoamericanos, adscrito a la Facultad de Filosofía y Letras de la UNAM.

\section{El Colegio de Estudios Latinoamericanos}

En agosto de 1977, el Consejo Técnico de la Facultad de Filosofía y Letras y el Consejo Universitario acordaron la creación del actual Colegio de Estudios Latinoamericanos (CELA). Desde entonces, - dicen sus historiadores- el colegio desarrolla un programa interdisciplinario en docencia, difusión e investigación, incorporando disciplinas tales como la historia, la filosofía, las letras y las ciencias sociales, para el estudio de América Latina y sus relaciones con la cultura y e historia universal, con fundamento en la historicidad de los procesos que la constituyen como región con numerosos rasgos en comunes.

El objetivo de la Licenciatura en Estudios Latinoamericanos es formar humanistas con una sólida base metodológica fundada en la historicidad de los procesos sociales y culturales como eje articulador de los aportes de la filosofía, la literatura y las ciencias sociales, capaces de producir conocimientos $\mathrm{y}$, con su práctica profesional, contribuir a transformar la región latinoamericana y caribeña. Según el perfil profesional definido:

El Licenciado en Estudios Latinoamericanos será un profesionista, interdisciplinario en humanidades, con apoyo en ciencias sociales, capaz de identificar y analizar problemáticas contemporáneas de América Latina con perspectiva histórica. Para ello se basará en el estudio de la Historia, la Filosofía, la Literatura y las Ciencias Sociales. El Licenciado en Estudios Latinoamericanos investigará la realidad histórico-cultural de la región, difundirá a través de los medios posibles las características de América Latina, enseñará esta cultura en sus 
múltiples vertientes, en los distintos niveles educativos, y propondrá alternativas y estrategias adecuadas en ámbitos públicos y privados relacionados con México y América Latina. (FFyL, 2018)

Desde esta perspectiva, el Colegio de Estudios Latinoamericanos contribuye en forma significativa a la redefinición de las humanidades en una estructura educativa tan importante como la Facultad de Filosofía y Letras de la UNAM. En este colegio se formaron intelectuales de calidad con orientación latinoamericana, multidisciplinarios y de muy diversas nacionalidades, no solo de América Latina, sino de diversas latitudes del planeta.

El CELA logró impactar en la creación de diversas redes nacionales e internacionales, de las cuales destacaría en este momento, solamente tres: la Sociedad de Estudios Sobre América Latina y el Caribe -SOLAR-, la Federación Internacional de Estudios Sobre América Latina y el Caribe -FIEALC- y la Red Continental de Pensamiento Latinoamericano. Instituciones que en acción conjunta con centros de investigación e instituciones universitarias nacionales e internacional promueven y difunden diversos estudios humanísticos por todo el mundo.

\section{Papel y función de las humanidades en la reforma educativa de la Cuarta Transformación}

La tendencia de la educación en México desde el gobierno de Salinas de Gortari fue incorporarse a los esquemas neoliberales que se impusieron a sociedad. Su característica fundamental estaría en eliminar de la educación su capacidad crítica y de incidencia en en la vida política y social; procurando adaptarla a los requerimientos laborales de los grandes centros que controlan la producción de mercancías a nivel mundial.

En esta perspectiva, Vicente Fox (Expresidente de México 2000-2006), mediante decreto presidencial del 8 de agosto de 2002 crea el Instituto Nacional para la Evaluación de la Educación (INEE), mismo que a partir 
del 26 de febrero de 2013, tras la reforma educativa de Peña Nieto, se convirtió en un organismo público autónomo, con personalidad jurídica y patrimonio propio, que controlaba la educación a nivel nacional y la encarrilaban en la perspectiva neoliberal.

Al resultar electo presidente de la República, Andrés Manuel López Obrador, se abrieron un conjunto de posibilidades trascendentes para la renovación de la Filosofía en particular, y de las humanidades en general en todo México, anulando la reforma educativa anterior. La propuesta de reforma educativa presentada por el actual Presidente de México, es el resultado de un conjunto de esfuerzos políticos y sociales, controvertidos, pues no todos están de acuerdo con las modificaciones que se implementarán en el campo educativo. En lo fundamental. La reforma modifica los artículos 3, 31 y 73 de la Constitución Política de los Estados Unidos Mexicanos, incorporando y derogando aspectos centrales que orientan la educación en una nueva dirección. Por ejemplo, el artículo tercero reformado señala:

Artículo 3o. Toda persona tiene derecho a la educación. El Estado -Federación, Estados, Ciudad de México y Municipiosimpartirá y garantizará la educación inicial, preescolar, primaria, secundaria, media superior y superior. La educación inicial, preescolar, primaria y secundaria conforman la educación básica; ésta y la media superior serán obligatorias, la educación superior lo será en términos de la fracción $\mathrm{X}$ del presente artículo. La educación inicial es un derecho de la niñez y será responsabilidad del Estado concientizar sobre su importancia. "Corresponde al Estado la rectoría de la educación, la impartida por éste, además de obligatoria, será universal, inclusiva, pública, gratuita y laica”. (DOF - Diario Oficial de la Federación Ley que reforma la educación en México. 2019)

Según esto, la educación superior le corresponde al Estado y tiene carácter obligatorio. Más tarde señala: 
La educación se basará en el respeto irrestricto de la dignidad de las personas, con un enfoque de derechos humanos y de igualdad sustantiva. Tenderá a desarrollar armónicamente todas las facultades del ser humano y fomentará en él, a la vez, el amor a la Patria, el respeto a todos los derechos, las libertades, la cultura de paz y la conciencia de la solidaridad internacional, en la independencia y en la justicia; promoverá la honestidad, los valores y la mejora continua del proceso de enseñanza aprendizaje. (DOF, ídem)

Y debemos destacar el inciso II C. que a la letra dice: “Contribuirá a la mejor convivencia humana, a fin de fortalecer el aprecio y respeto por la naturaleza, la diversidad cultural, la dignidad de la persona, la integridad de las familias, la convicción del interés general de la sociedad, los ideales de fraternidad e igualdad de derechos de todos, evitando los privilegios de razas, de religión, de grupos, de sexos o de individuos" (DOF, ídem)

En la iniciativa de López Obrador, se establece por primera vez en la constitución la figura de "interés supremo" de la educación para niños y jóvenes, guiado por principios de integralidad, equidad y excelencia. Además, establece que el Estado apoyará la investigación y la innovación científica, humanística y tecnológica. La propuesta incluye la atención prioritaria al fortalecimiento de las escuelas normales y las instituciones de educación superior.

Como parte del impulso a una "educación cultural", se incorpora en los planes de estudios, de manera obligatoria, la enseñanza de civismo, valores, la cultura, el arte, la música, el deporte y el respeto al medio ambiente. La reforma pone énfasis en la educación indígena, bilingüe y bicultural; y para evitar la deserción de los alumnos en el nivel medio superior y promover su permanencia en las escuelas, el gobierno apoyará a los estudiantes con un amplio sistema de becas. 


\section{La Universidad Autónoma del Estado de México}

La Universidad Autónoma del Estado de México (UAEMéx) posee una, más que, centenaria tradición humanística y una firme vocación por contribuir al desarrollo de los más altos valores de nuestros espíritus. En 1828 se constituyó en la ciudad de Toluca, el Instituto Literario, para "la enseñanza de todos los ramos de instrucción pública" (Colección de decretos y órdenes del Congreso del Estado de México, 848. p. 26); aunque, de manera oficial, el 5 de marzo de 1857 se instituyó la Academia de Humanidades. Debemos destacar que entre 1834 y 1835, el Instituto fue dirigido por el poeta cubano José María Heredia (1803-1839). En 1886, el Lic. Zubieta (gobernador interino del Estado de México) lo denominó Instituto Científico y Literario del Estado de México. En 1899, la institución cambió nuevamente de nombre, esta vez por el de Instituto Cientifico y Literario Porfirio Díaz del Estado de México; para en 1910 regresar a ser simplemente, Instituto Científico y Literario.

El 13 de marzo de 1956, el gobernador Salvador Sánchez Colín envió a la XXXIX Legislatura Local, la Ley Orgánica de la Universidad Autónoma del Estado de México, misma que se aprobó el 16 de marzo y entró en vigor el 21 de marzo.

En 1967 inicia sus actividades la Escuela de Filosofía y Letras, que ofrecía las carreras de Letras, Historia y Filosofía; pero en 1970 cambio su nombre a Instituto de Humanidades; hasta que en 1977 se establece definitivamente como Facultad de Humanidades; a la que actualmente se adscriben las licenciaturas en Filosofía, Lengua y Literatura Hispánicas, Historia, Ciencias de la Información Documental, y Artes Teatrales. Anteriormente estaban integradas las carreras de Psicología, Geografía, Turismo y Antropología; no obstante, a lo largo de los años fueron separándose de Humanidades para actuar de manera independiente.

Las actividades de posgrado alcanzaron en forma temprano gran relevancia, es así que el primer posgrado que se aprobó en la Facultad 
de Humanidades fue la Maestría en Estudios Latinoamericanos (1974); años más tarde se creó el Programa de Maestría y el Doctorado en Humanidades. En la actualidad se ofertan los siguientes programas: Maestría en Humanidades - Ética Social, Maestría en Humanidades - Filosofía Contemporánea, Maestría en Humanidades - Estudios Históricos, Maestría en Humanidades - Estudios Latinoamericanos, Maestría en Humanidades-Estudios Literarios. Anivel doctoral se ofrecen los doctorados en Humanidades con énfasis en Ética Social, Filosofía Contemporánea, Estudios Históricos, Estudios Latinoamericanos y, Estudios Literarios.

En el caso particular de la Licenciatura en Filosofía, debemos señalar que, en esta perspectiva, nuestra Licenciatura ha creado la posibilidad de incorporar en su malla curricular áreas del pensamiento latinoamericano, áreas de estudio del pensamiento de nuestros pueblos originarios, de las culturas de los diversos pueblos originarios de América Latina y el Caribe. Hecho que resulta trascendental, dado que la gran mayoría de las facultades de filosofía y/o humanidades, se caracterizan por una marcada tendencia eurocéntrica y civilizatoria. 


\section{Referencias bibliográficas}

Bellón, G. (2001), Reseñas a Marsiske, R. (2001) Coordinador, La universidad de México. Un recorrido histórico de la época colonial al presente, CESU-UNAM/Porrúa, México, en Perfiles educativos vol.23 no.93 México. En http:// www.scielo.org.mx/scielo.php?script=sci_arttext\&pid $=$ S0185-26982001000300008 Consultado el 9 de junio de 2019.

Barreda, G. (2003). Oración Cívica. Editorial del Cardo, Biblioteca Virtual Universal. Argentina. en https:/www.biblioteca.org.ar/ libros/1112.pdf Consultado el 6 de febrero de 2020.

Bautista Alvarado, S.D.:(2008) "Habilidades de dirección del servidor público, en la Facultad de Estudios Superiores Acatlán de la Universidad Nacional Autónoma de México", Edición electrónica gratuita. Texto completo en www.eumed.net/ tesis/2008/sdba/

Descripción sintética del plan de estudios de la Licenciatura en Estudios Latinoamericanos, Facultad de Filosofía, Colegio de Estudios Latinoamericanos, UNAM, 2018, en https:/escolar1.unam. mx/planes/f_filosofia/Estud-lat.pdf mayo de 2019.

Des-Informémonos, (2019), México memorias de la huelga de la UNAM a 20 años. En: https://desinformemonos.org/mexicomemorias-de-la-huelga-de-la-unam-a-20-anos/) Consultado el 2 de febrero de 2020.

Diario Oficial de la Federación, (2019) Ley que reforma la educación en México, México, 15 de mayo. En https:/www.dof.gob. $\mathrm{mx} /$ nota_detalle.php? codigo $=5560457 \&$ fecha $=15 / 05 / 2019$ consultado el 7 de noviembre de 2019.

Des-Informémonos, (2019), "México memorias de la huelga de la UNAM a 20 años" 26 de abril de 2019. Recuperado de: https://desinformemonos. org/mexico-memorias-de-la-huelga-de-la-unam-a-20-anos/) 
Escuela Cima (s/f). Universidad Real y Pontificia de México. En http:// www.escuelacima.com/universidadrealypontificia.html consultado el 9 de junio de 2019.

Facultad de Filosofía y Letras, (2018), Descripción sintética del plan de estudios licenciatura en estudios latinoamericanos. UNAM, México En https://escolar1.unam.mx/planes/f_filosofia/Estud-lat.pdf. Consultado el 2 de febrero de 2020.

Facultad de Humanidades, Universidad Autónoma del Estado de México, Antecedentes Históricos. En http://humanidades.uaemex.mx/ antecedentes-historicos/ Consultado el 10 de junio de 2019.

García Morales, A. (1992). El Ateneo de México 1906 - 1914. Orígenes de la cultura mexicana contemporánea. (Imprenta E.E.H.A.). Sevilla.

Machuca, R. (2007) Reseña del Colegio de Estudios Latinoamericanos. México. en Latinoamericanos, México, https:// latinoamericanos.wordpress.com/entradas-extensas/\#titulo1 mayo de 2019.

Marsiske, Renate (2006). La universidad de México: Historia y Desarrollo. Revista Historia de la Educación Latinoamericana, 8,11-34. [fecha de Consulta 8 de junio de 2019]. ISSN: 01227238. Disponible en: https:/www.redalyc.org/articulo. oa? id=869/86900802

Méndez Plancarte, G. (1945). Humanismo del siglo xviii. (Tesauro). Tomo I. No. 2. México.

Méndez Plancarte, Gabriel, (1944), Índice del Humanismo Mexicano, en Ábside, Revista de Cultura Mexicana, viii - i (enero-marzo, 1944).

México: memorias de la huelga de la UNAM a 20 años. 26 de abril de 2019. En desinformémonos.org. https://desinformemonos.org/ mexico-memorias-de-la-huelga-de-la-unam-a-20-anos/ mayo de 2019. 
Ocampo López, Javier. (2005): “José Vasconcelos y la Educación Mexicana", en Revista Historia de la Educación Latinoamericana No. 7, Tunja, Universidad Pedagógica y Tecnológica de Colombia. RUDECOLOMBIA.

Rojas Galván, J. (2016). "Hacia la restauración de modelo humanista de la Educación en México: una propuesta con el potencial de formar hombres y mujeres cultos", en Sincronía, Año XX. Número 69 Enero-Junio, México.

Valadés, D. (1914). Justo Sierra y la fundación de la Universidad. (UNAM) México. en https://archivos.juridicas.unam.mx/ www/bjv/libros/8/3634/14.pdf mayo de 2019

Vargas Lozano, G. (s/f), El positivismo en México: significado, función y declinación; en Enciclopedia de la filosofía mexicana. Siglo XX, http:/dcsh.izt.uam.mx/cen_doc/cefilibe/images/banners/ enciclopedia/Diccionario/Corrientes/ElpositivismoenMexicoVargasLozano_Gabriel.pdf 19 de abril de 2019. Consultado el 6 de febrero de 2020.

Vásquez, J. (1970). Nacionalismo y Educación en México. (El Colegio de México). México.

Zea, L. (1976). El Pensamiento Latinoamericano. (Ed. Ariel). Barcelona. . (1985). El positivismo y la circunstancia mexicana. (SEPFCE). México. 